\title{
Emprendimiento turístico rural y asociatividad: estudio en base a experiencias en chile y el mundo.
}

\section{Luis Fernando Romero Álvarez ${ }^{1} \&$ Francisco Ricardo Mesa Mesina ${ }^{2}$.}

1) Egresado de Ingeniería Comercial de la Universidad de Los Lagos, Osorno, Chile. Email: lfromero@telsur.cl

2) Académico del Departamento de Ciencias Administrativas y Económicas de la Universidad de Los Lagos, Osorno, Chile. Email: fmesa@ulagos.cl

\section{Resumen}

El desarrollo de la actividad turística en las décadas recientes ha dado lugar a una amplia gama de formas de turismo. El turismo rural constituye un ejemplo de esta tendencia, el cual se distingue por un contacto respetuoso con el entorno natural y una interrelación con la población local. Esta forma de turismo surge en un contexto de diversificación productiva, la cual da lugar a la innovación y a la integración de actividades; así como también surge ante una revalorización de lo rural. Esta actividad tiene sus orígenes en Europa, siendo Francia y España los países en donde presenta un mayor nivel de desarrollo. En estos países, sobresale el incentivo al emprendimiento por medio de ayudas económicas destinadas tanto a los residentes rurales como a los municipios; además de propiciarse la asocaitividad. En los países americanos, el turismo rural es aún una novedad, destacándose que sólo Argentina, Chile y México cuentan con políticas claras esta área; en este sentido, sobresale la creación de circuitos agroturísticos en torno a un producto clave. En Chile, sobresale el emprendimiento por parte de pequeños productores y la creación de redes de turismo rural.

Palabras clave: turismo rural, diversificación agropecuaria, asociatividad, emprendimiento.

\section{Abstract}

The development of tourism in recent decades had led many types of tourism. Rural tourism is an example of this situation and this type of tourism is characterized by a respectful contact with the natural environment and interaction with the local people. Rural tourism arises in a context of 
agricultural diversification, which leads to innovation and incorporating activities; and also, rural tourism comes with a revaluation of rural. This activity has its origin in Europe; specifically, in France and Spain has a higher level of development. In these countries, there are economics incentives for entrepreneurship destined to rural people and municipalities; and also, France and Spain promotes associativity. In the Americas, rural tourism is still a novelty; only Argentina, Chile and Mexico have strong public programs on this issue. In these countries, there are touristic routes around a key food. In Chile, rural touristic entrepreneur are small farmers and they are networking in touristic routes.

Key words: rural tourism, agricultural diversification, associativity, entrepreneurship.

\section{Introducción}

El turismo es una de las industrias de más rápido crecimiento a nivel mundial. Según la Organización Mundial del Turismo (2013), en 2012 las llegadas de turistas internacionales a nivel mundial ascienden a la cantidad de 1.035 millones de turistas, siendo el primer año en que se superaron los mil millones; asimismo, en materia de ingresos por turismo internacional, la OMT indica que éstos ascienden a la suma de 1 billón 75 mil millones de dólares, registrándose un crecimiento sostenido y correlacionado de los ingresos en relación a las llegadas.

En Chile, el turismo ha dejado de ser una actividad poco relevante para convertirse en una valiosa fuente de ingresos y empleo, contribuyendo con un 3,2\% del PIB en 2010 y un 3,8 del total del empleo nacional en 2011 (SERNATUR, 2012). La OMT (2013) señala que Chile acogió en 2012 a 3,55 millones de personas provenientes del extranjero y recibió 2.201 millones de dólares de ingresos por turismo por turismo internacional; visitantes que llegan motivados por conocer la naturaleza y la cultura local. Sin lugar a dudas, la minería genera las principales exportaciones del país; no obstante, el turismo se posiciona el cuarto lugar y supera a exportaciones emblemáticas como el vino o el salmón (SERNATUR, 2012). Sin embargo, son los propios chilenos los principales visitantes del país; en concreto, el 70\% de la actividad turística en 2011 (SERNATUR, 2012).

El desarrollo de la actividad turística en las décadas recientes ha implicado una elevada segmentación del mercado turístico, hecho que da lugar a una amplia gama de formas de turismo. En este contexto, adquiere notoriedad el concepto de "turismo de intereses especiales", el cual SERNATUR (2008) define como "tipos de viajes basados en motivaciones específicas más allá de los objetivos habituales de los viajes turísticos o de vacaciones". Un ejemplo de esta nueva tendencia en turismo constituye el turismo rural, el cual Barrera (2006) define como "aquella actividad turística realizada en el espacio rural, compuesto por una oferta integrada de ocio dirigida a una demanda cuya 
motivación incluye el contacto respetuoso con el entorno natural y una interrelación con la población local".

Observando este fenómeno desde el sector silvioagropecuario, Barrera (2006) señala que el turismo rural surge en un contexto de diversificación productiva, tendencia global que ha encontrado acogida especialmente entre los productores de menor escala, quienes han perdido competitividad en la producción de commodities a pesar del aumento de sus precios. De este modo, la diversificación da lugar a la innovación y a la integración de actividades, especialmente en quienes no pueden aprovechar las ventajas de las economías de escala. Adicionalmente, el turismo rural surge paralelamente a una revalorización de lo rural entre los habitantes de las ciudades. Barrera señala que una forma de vincular la producción primaria con el turismo consiste en las rutas alimentarias, definidas por él mismo como "un itinerario que permite reconocer y disfrutar de forma organizada el proceso agropecuario, industrial y la degustación de la cocina regional, expresiones de la identidad cultural". Estos circuitos se organizan en torno a un producto clave, una canasta de productos o un plato característico de la localidad.

\section{Materiales y Métodos}

Se procedió a una revisión de experiencias de turismo rural, las cuales corresponden a los países europeos de Francia y España; en el continente americano, Argentina, Colombia y Estados Unidos; y en Chile, las experiencias de Chiloé, Linares, Colchagua, San Pedro de Atacama y Corral. Los casos estudiados fueron obtenidos de diversas fuentes bibliográficas y audiovisuales y fueron resumidas a fin de exponer los aspectos centrales de cada situación; es decir, se expone el origen del turismo rural en estos territorios, los instrumentos utilizados en el desarrollo de la actividad y los aspectos distintivos de cada experiencia.

Resultados

El turismo rural en Europa es una actividad en expansión, aunque con distintos grados de desarrollo entre los países del continente. Solsona (2006) señala que el impulso al turismo rural ha estado marcado por el apoyo tanto de la Comunidad Europea como por los gobiernos locales, así como por el trabajo coordinado entre el sector público y el privado; asimismo, las inversiones públicas han 
consistido mayoritariamente en incentivos a los emprendimientos, resultando beneficiados, en gran medida, los pequeños propietarios.

Concretamente, Blanco (1996) señala, a nivel comunitario, los "Fondos Estructurales" $\left(\right.$ FEOGA $^{1}$, FEDER $^{2}$ y FSE ${ }^{3}$ ) y los programas LEADER. Según Blanco, los aspectos clave de estos programas en materia de turismo rural son: la formación de estructuras estables de asociación, las cuales favorecen la participación de los agentes locales implicados; la organización de una escala productiva pertinente, logrando el equilibrio entre singularidad, calidad y sustentabilidad; la ordenación territorial, destinando espacios para distintos usos en materia turística; el conocimiento del sector, especialmente de su oferta y su demanda; la definición y armonización de criterios y símbolos de calidad para los diferentes productos; la orientación de las ayudas económicas hacia las formas sostenibles de turismo; la armonización de los diferentes tipos de trato fiscal hacia los agentes del turismo rural; los aspectos de seguridad y salud; y, por último, el respeto a la competencia leal.

Solsona señala que el turismo rural ha permitido generar dinamismo económico en áreas poco desarrolladas, contribuyendo a la cohesión económica, social y territorial. No obstante, los aspectos de mayor dificultad han sido la falta de conceso a la hora de definir los productos, la profesionalización de la actividad y el establecimiento de políticas de promoción mejor desarrolladas. Los países que lideran esta actividad a nivel europeo y, además, mundial, son Francia y España.

Francia constituye el primer destino turístico internacional, recibiendo a 79,5 millones de visitantes en 2012 (OMT, 2013). Fourneau (1998) destaca que, en este país, el vínculo entre alimentos y turismo ha sido históricamente estrecho, ejemplo de esto son las múltiples denominaciones de origen existentes en quesos y vinos. Según Fourneau, el surgimiento del turismo rural en Francia consta de dos etapas: la primera, entre los años treinta y cincuenta, se caracterizó por un desarrollo espontáneo y difuso de esta actividad; la segunda etapa, a partir de los años sesenta, se caracteriza por un desarrollo voluntario y organizado de esta actividad a partir de una serie de reflexiones y actuaciones en temas de políticas turísticas y ordenamiento territorial.

De esta manera, el Estado Francés ha incentivado la creación y mejora de infraestructura turística por medio de exoneraciones fiscales, subsidios y préstamos, ayudas destinadas a las propiedades de los habitantes rurales como a los espacios comunes a cargo de los municipios. Otro aspecto fundamental de la experiencia francesa ha sido la asociatividad; al respecto, Fourneau destaca que el desarrollo turístico de una determinada zona geográfica se realiza mediante los P.S.O. ("Pôles de Séjours Organisés", es decir, "Grupos Organizados de Descanso"), que consiste en la asociación de

\footnotetext{
${ }^{1}$ Fondo Europeo de Orientación y Garantía Agrícola.

${ }^{2}$ Fondo Europeo de Desarrollo Regional.

${ }^{3}$ Fondo Social Europea.
} 
un grupo de municipios afines, permitiendo la planificación, ordenación y desarrollo en conjunto del turismo rural.

Los habitantes rurales pueden afiliarse a la "Féderation Nationale Gîtes de France" ("Federación Nacional de Casas de Campo de Francia"), que es el ente coordinador nacional y regional de las diversas personas oferentes de turismo rural. Entre los aspectos clave de su funcionamiento, Barrera (2006) destaca la calidad, el apoyo técnico, la comercialización y promoción, y la fijación conjunta de los precios entre los afiliados y la organización, a fin de mantener la rentabilidad del negocio de los habitantes rurales.

En España, el turismo rural ha surgido como consecuencia de la aplicación de los programas de la Comunidad Europea, dando posterior lugar a iniciativas provenientes del Estado. Mondéjar et al (2007) mencionan que estos programas apuntan a "mejorar la organización de los oferentes y la comercialización, estimular una oferta turística más elaborada e integrar el turismo con la actividad agraria". El impacto de estos programas ha sido favorable, permitiendo dinamizar zonas rurales desfavorecidas. A diferencia de Francia, en España no existe una única institución coordinadora del turismo rural, sino que existen diversas asociaciones según las regiones geográficas del país; de este modo, una dificultad consiste en la carencia de criterios uniformes a nivel estatal (Cánoves y Villarino, 2000). Una de las asociaciones más representativas de la actividad la constituye "Nekazalturismoa" (“Turismo Rural”), en el País Vasco; cuya misión es, según lo menciona el sitio web de la misma asociación, "desarrollar, impulsar y promocionar un producto turístico de calidad, con características propias, de tal forma que se valore y se diferencia de otros productos en el mercado". Su funcionamiento es similar al sistema francés "Gîtes de France", con idénticos requisitos de afiliación y estrategias de comercialización. Al ser el turismo rural una actividad relativamente nueva en España, Cánoves y Villarino señalan dos principales dificultades: la carencia de criterios uniformes a nivel estatal, afectando la calidad de los productos; y la estacionalidad de la actividad, predominando las visitas en la temporada estival.

En los países americanos, el turismo rural es aún una novedad, encontrándose los productos en plena etapa de desarrollo. Según Barrera (2006), todos los países del continente cuentan con establecimientos turísticos en las zonas rurales, registrándose un notorio crecimiento de la actividad y el interés por esta entre los residentes del espacio rural. No obstante, los países de la región no cuentan con políticas claras en esta temática, salvo Argentina, Chile y México. En Argentina, Navarro y Schlüter (2010) mencionan que a fines de los años noventa comenzó la aplicación de los programas estatales de apoyo al turismo rural, entre los cuales sobresale "Rutas Alimentarias Argentinas", el cual consiste en la organización de circuitos turísticos en torno a un producto o un plato, en un territorio geográfico y culturalmente afín. 
Un caso destacado de estas rutas lo constituye la "Ruta de la Yerba Mate", la cual se localiza en las provincias norteñas de Misiones y Corrientes, zona productora de yerba mate. Barrera (2009) señala que esta ruta integra a diversos agentes relacionados con la yerba mate y el turismo, tales como agricultores, agroindustrias, restaurantes, alojamientos, entre otros. De esta manera, se vincula la producción primaria con el turismo, donde éste cumple el rol de promotor de los alimentos locales, estimulando la agregación de valor. Barrera enfatiza que la creación de esta ruta ha sido fruto de un proceso participativo de los agentes involucrados; de este modo, se ha obtenido el diseño consensuado de los protocolos de calidad para cada sector (agroindustrias, restaurantes, alojamientos, etc.), el desarrollo de nuevos productos en base a la yerba mate, la realización de un concurso gastronómico para la elección del menú obligatorio y la selección de la imagen corporativa, entre otras cosas.

En Colombia, cabe destacar el caso del Eje Cafetero, región en donde las haciendas cafeteras han desarrollado el turismo rural como una opción de desarrollo frente a la crisis del café. Según Barrera (2006), pese a que este país no cuenta con políticas nacionales de apoyo al turismo rural, el desarrollo espontáneo de esta actividad en el Eje Cafetero ha dado lugar a un trabajo conjunto entre el sector público y el privado en dicha zona. Barrera menciona que, desde mediados de los años noventa, el desarrollo de esta actividad ha estado marcado por "la existencia de procesos de planificación, la articulación del trabajo entre el sector público y el privado, la continuidad de procesos, una importante inversión privada y una agresiva campaña promocional”.

Cabe destacar dos aspectos clave en el desarrollo turístico del Eje Cafetero: la asociatividad y la calidad, aspectos que se entrelazan en el "Club de Calidad Haciendas de Café”. Según lo señala el sitio web de la organización ${ }^{4}$, para el sector público consiste en un "programa de política turística que asesora y promociona, de forma dirigida y tutelada, una parte del subsector de alojamiento para que revierta beneficios sobre toda la industria turística del destino"; al mismo tiempo, para el sector privado es una "agrupación selectiva de establecimientos que, bajo un concepto de hotelería, presentan y mantienen unos estándares de calidad específicos; facilita su acceso a mercados más rentables de forma conjunta y mejoran los resultados de sus negocios". Según OMT (2003), el Eje Cafetero se ha convertido en el segundo destino turístico de Colombia tras Cartagena de Indias; no obstante, una debilidad que presenta es que el sistema productivo de café modificó mucho la naturaleza, lo que contrasta con otras zonas del país en donde el café se cultiva en un entorno rodeado de especies nativas.

Otro caso interesante en el continente americano lo constituye "Santa Barbara Wine Country" ("Ruta del Vino del Valle de Santa Bárbara"), en California, Estados Unidos. Este recorrido es el

\footnotetext{
${ }^{4}$ Sitio web del "Club de Calidad Haciendas de Café" http://www.clubhaciendasdelcafe.com/club.php (Visitado el 27 de octubre de 2014).
} 
escenario de la película de Payne (2004) "Sideways" ("Entre copas"), la cual muestra el recorrido de los amigos por este circuito turístico. La emisión esta película ha impactado tanto la actividad turística en Santa Bárbara como la industria vitivinícola, cambiando las preferencias de los consumidores en concordancia a lo exhibido en el filme, siendo un claro ejemplo del impacto de los medios de comunicación masivos en la actividad turística. A modo de ejemplo, Brown (2009) destaca los cambios en las ventas de las variedades de vino merlot y pinot como según las preferencias de los personajes de la película; desplomándose las ventas de merlot y aumentando considerablemente las de pinot el año siguiente del estreno de la cinta. Asimismo, Martin (2009) estima que entre el 10\% y el $15 \%$ de los visitantes llegan a conocer los parajes y establecimientos exhibidos en la película.

En cuanto a Chile, la OMT señala que el país poseía en 2003 un total de 450 establecimientos de turismo rural, recintos que son en su mayoría "pymes" y generan una planta turística de aproximadamente 2.200 camas; SERNATUR (2003) añade que el 20\% de los ingresos recibidos por estos emprendedores proviene directamente del turismo. Schaerer y Dirven destacan que en Chile la mayoría de estos emprendedores son mujeres, esto se debe a que ellas suelen tener escasa participación en las labores agropecuarias tradicionales, estando disponible para otras ocupaciones. Herrera (2009) señala que, en el país, los casos más reconocidos de esta actividad son la "Ruta de Turismo Rural Chiloé", “Turismo rural Achibueno" (Provincia de Linares), "Ruta del Vino del Valle de Colchagua", "Turismo Rural Licanhuasi" (San Pedro de Atacama) y "Turismo Rural CorralChaihuín" (Provincia de Valdivia).

La Red de Turismo Rural de Chiloé es la primera iniciativa en su tipo surgida en Chile. Schaerer y Dirven (2001) mencionan que esta red surgió en 1995 a raíz de las conversaciones entre el Obispo de Ancud y el Ministro de Agricultura de la época, quienes sabían de experiencias similares en Europa. La red se concretó con el apoyo técnico y financiero de diversos organismos estatales, del gobierno del País Vasco (España) y con la coordinación del Obispado de Ancud. Casas (2004) señala que se ubicó familias que vivieran en un lugar con gran belleza paisajística y que estuvieran dispuestas a involucrarse en una actividad nueva, logrando integrar a 27 familias que iniciaron las operaciones en el verano de 1997; cabe destacar que la red se creó como una asociación gremial, con RUT propio y con cada participante como sucursal.

Schaerer y Dirven señalan que los comienzos fueron modestos, registrándose visitantes en sólo ocho casas en la primera temporada; no obstante, en la tercera temporada la cifra fue casi el doble. Estos autores destacan que la experiencia ha sido positiva no sólo en el ámbito económico, sino también en el aspecto sociocultural; es decir, las familias participantes no sólo han mejorado sus condiciones de vida a causa de las mejoras de sus viviendas y los ingresos percibidos, sino también ha surgido una revalorización de la cultura rural chilota. No obstante, Schaerer y Dirven indican que es 
necesario trabajar en aspectos de capacitación, comercialización, calidad, coordinación y en un mejor aprovechamiento del patrimonio cultural de Chiloé.

Respecto a la Red de Turismo Rural Achibueno, ésta se ubica en la vega del río homónimo, en la zona cordillerana de la Provincia de Linares. Schaerer y Dirven mencionan que esta red se desarrolla en una extensión de aproximadamente veinte kilómetros, en un recorrido que se caracteriza por contar con cabañas, restaurantes y diversos camping en la ribera del río, el cual cuenta con una poza apta para el baño. Esta red surgió con el apoyo de INDAP, FOSIS y FIA, además de la Federación Esperanza Campesina; las tres primeras instituciones han asistido principalmente con el otorgamiento de créditos, subsidios y transferencia tecnológica, en cuanto a ésta última, cabe destacar los hornos de barro con eficiencia energética. Saavedra (2012) menciona que, a fines de 2012, la red inauguró sus oficinas en la ciudad de Linares, en las inmediaciones de la Gobernación Provincial; hecho que contribuye a la promoción y comercialización del circuito.

Por otra parte, la Ruta del Vino de Colchagua es el primer circuito turístico del vino en Chile, creado en 1996. Herrera (2009) señala que esta ruta cuenta con 18 viñas asociadas y con las oficinas centrales de la asociación en la ciudad de Santa Cruz, desde donde se comercializa y promociona los tours hacia las viñas participantes. Herrera destaca que existen diversas modalidades para recorrer esta ruta, apuntando a satisfacer los intereses de diversos tipos de visitantes, caracterizados como "aficionados", "conocedores" y "fanáticos". En este sentido, la ruta se caracteriza por la heterogeneidad de sus servicios y la sofisticación de éstos, siendo posible mencionar la existencia de paseos en coches antiguos, recorridos en teleférico, vistas al cielo por medio de telescopios, degustaciones a ciegas o actividades de vinoterapia, por mencionar algunos ejemplos.

Zamora y Barril (2007) mencionan que la apertura al turismo por parte de las viñas de Colchagua ha tenido como motivación no sólo el aumento de las ventas, sino también estabilidad y diversificar los ingresos. Estos autores señalan que los inicios no fueron fáciles debido a que pasar de la agricultura tradicional al turismo no fue sencillo para las viñas participantes; siendo las viñas boutiques las pioneras en esta actividad. Herrera señala que el desarrollo de esta ruta ha contado con el apoyo de diversos programas y proyectos del Estado, concretamente, del organismo CORFO. Estos programas han apuntado hacia favorecer los aspectos de asociatividad, sustentabilidad y la coordinación entre el sector público y el privado; de este modo, se espera que "el Valle de Colchagua sea reconocido como una zona productora de vinos de calidad, generados en un espacio rural en armonía ambiental, económica y sociocultural” (Herrera, 2009).

Otra experiencia interesante es la Red de Turismo Rural Licanhuasi, ubicada en la comuna de San Pedro de Atacama, en la zona norte de Chile. Morales menciona que esta red fue creada en 1999 a partir de la iniciativa de las 22 comunidades indígenas de la zona, quienes percibieron la necesidad de participar en la creciente industria turística local. Esta red se creó con el apoyo técnico y financiero de 
INDAP, CONADI, SERCOTEC, FOSIS, SERNATUR y el Fondo de las Américas (FDLA), apuntando hacia una revalorización de los recursos económicos, sociales y ambientales del altiplano chileno. Morales destaca que este proyecto unió los aspectos productivos y los aspectos ambientales de modo complementario; en concreto, las acciones desarrolladas en los inicios estuvieron dirigidas a capacitar en ecoturismo, desarrollar liderazgo ambiental, instalar infraestructura turística, capacitar en gestión, promover la asociatividad, motivar la sinergia entre el sector público y privado, desarrollar estrategias de comercialización y prestar asesoría técnica en todos los ámbitos anteriores. De esta manera, las comunidades indígenas coordinan una oferta turística que, en un plazo de dos años, logró generar alrededor de 70 empleos directos, además de atraer un volumen considerable de recursos provenientes de la industria minera. Morales destaca que el desarrollo de estos emprendimiento y la activación de la red han significado para las familias integrantes, además del aumento de sus ingresos, la revalorización de sus cultivos tradicionales y de la ganadería local.

Por otra parte, la comuna de Corral, en la costa de la Provincia de Valdivia, cuenta con una red de turismo rural entre las localidades de Corral y Chaihuín, circuito que se caracteriza por seguir un recorrido paralelo a la costa, complementando los atractivos propios del ambiente campesino con los atractivos ligados al mar. Asimismo, la cercanía con la Reserva Costera Valdiviana es un elemento favorecedor de esta red, dado que acceder a aquella reserva, de gran valor ecológico, es necesario transitar por el mismo camino. Herrera (2009) menciona que la red se estableció en 1999 con el apoyo técnico y financiero de INDAP y FIA, y con la participación inicial de 25 familias, a quienes se les hizo participar de un programa de capacitación en diversas temáticas relacionadas al manejo de un emprendimiento turístico. Herrera indica que en 2009 quedaban 16 familias de las 25 iniciales, lo que se debe, por una parte, al incumplimiento de la normativa interna de la organización, y por otro lado, a la menor afluencia de turistas que la esperada a causa de los problemas de accesibilidad. No obstante, Herrera destaca que las familias restantes manifiestan iniciativa en mejorar su servicio, en especial en el desarrollo de los aspectos ecológicos vinculados a sus emprendimientos.

Sin lugar a dudas, el principal impacto del turismo rural ha sido contribuir a cambiar las percepciones respecto al espacio rural, haciendo de éste un territorio generador de nuevas oportunidades económicas, en un marco de armonía sociocultural y medioambiental. En el ámbito económico, esta actividad ha generado nuevas fuentes de empleo e ingreso, mejorando las condiciones de vida de los habitantes del medio rural. El agroturismo, al ser una extensión de la actividad agropecuaria preexistente, añade valor a la producción y permite el aprovechamiento de recursos ociosos. En el ámbito sociocultural, el turismo rural ha permitido generar arraigo en el espacio rural y ha abierto nuevas oportunidades para las mujeres y los jóvenes. Además, ha permitido rescatar la cultura y el patrimonio local, generándose un mutuo enriquecimiento cultural a partir del encuentro entre visitantes y residentes. En el ámbito ambiental, el turismo rural facilita la introducción de criterios de sustentabilidad en la actividad silvioagropecuaria; debido, por una parte, a la necesidad de 
mantener un entorno de calidad paisajística y, por otro lado, a la necesidad de satisfacer a una clientela con intereses especiales en materia turística.

Las experiencias analizadas demuestras que el emprendimiento turístico rural se ve favorecido con la coordinación entre el sector público y el privado, además del apoyo técnico y económico de otras instituciones; el desarrollo de la asociatividad entre los emprendedores y la profesionalización de la actividad en éstos; la integración de los elementos culturales propios de cada zona y el equilibrio entre tradición e innovación. No obstante, la instalación de infraestructura turística no basta por sí sola, siendo imprescindible conocer la demanda de esta forma de turismo a fin de entrar adecuadamente al mercado turístico y asegurar la rentabilidad de la actividad.

\section{Referencias}

Barrera, E. 2006. Turismo rural, un agronegocio para el desarrollo de territorios rurales. En: Vieites, C. Agronegocios alternativos. Enfoque, importancia y bases para la generación de actividades agropecuarias no tradicionales. Editorial Hemisferio Sur, Buenos Aires, Argentina. 464 pp.

Barrera, E. 2009. Las Rutas Alimentarias como instrumento para el desarrollo territorial: el caso de la Yerba Mate de Argentina. Revista Universidad de Sonora, México. 26:19-22.

Blanco, F. 1996. Fundamentos de la política comunitaria y española en materia de turismo rural. Estudios Turísticos, Instituto de Estudios Turísticos, España. 131:25-49.

Brown, Ch,. 2008. Santa Barbara Wine Country: Behind the Scenes, Food \& Wine, Time Inc., Estados Unidos. Disponible en http://www.foodandwine.com/articles/behind-the-scenes-in-santa-barbara (Visitado el 28 de octubre de 2014).

Casas P. 2004. Bases técnicas para la implementación de una red de turismo rural en el complejo Malleco-Tolhuaca, IX Región. Tesis de Pregrado. Facultad de Ciencias Forestales, Universidad de Chile. Santiago, Chile. 136 pp.

Cánoves, G., \& M. Villarino, 2000. Turismo en espacio rural en España: actrices e imaginario colectivo. Documents d'Anàlisi Geogràfica, Universidad Autónoma de Barcelona, España. 37: 51-77.

Forneau, F., 1998. El turismo en espacio rural en Francia, Cuadernos de Turismo, Universidad de Murcia, España. 1:41-53.

Herrera, R., 2009. Estudio sobre el turismo rural en Chile, Instituto Interamericano de Cooperación para la Agricultura (IICA), Valdivia, Chile. 130 pp. 
Martin, H., 2009. They're still toasting "Sideways" in Santa Barbara Wine Country, Los Angeles Times, California, Estados Unidos. Disponible en: http://articles.latimes.com/2009/sep/03/business/fisideways 3 (Visitado el 28 de octubre de 2014).

Mondéjar, J., J. Mondéjar, \& M. Vargas, 2007. Análisis del turismo rural en Castilla-La Mancha (España). El impacto de los programas europeos de desarrollo rural LEADER y PRODER. Estudios y Perspectivas en Turismo, Universidad de Castilla-La Mancha, España. 17:359-373.

Morales, F., 2006. Turismo comunitario: una nueva alternativa de desarrollo indígena. Revista de Antropología Iberoamericana, Madrid, España. 1:249-264.

Navarro F. \& R. Schlüter, 2010. El turismo en los pueblos rurales de Argentina, ¿es la gastronomía una opción de desarrollo?. Estudios y Perspectivas en Turismo, Centro de Investigaciones y Estudios Turísticos, Buenos Aires, Argentina. 19:909-929.

Organización Mundial del Turismo. 2003. El turismo rural en las Américas y su contribución a la creación de empleo y a la conservación del patrimonio, Publicaciones Organización Mundial del Turismo, Madrid, España. 304 pp.

Organización Mundial del Turismo. 2013. Panorama OMT del turismo internacional. Publicaciones Organización Mundial del Turismo, Madrid, España. 16 pp.

Saavedra, M. 2012. Cámara de Turismo Rural implementó oficinas con proyecto financiado por el FOSIS. Archivo de noticias del Fondo de Solidaridad e Inversión Social, Ministerio de Desarrollo Social, Chile. Disponible en http://www.fosis.cl/index.php/archivo-historico-noticias/archivo-noticias2012/1963-camara-de-turismo-rural-implemento-oficinas-con-proyecto-financiado-por-el-fosis

(Visitado el 28 de octubre de 2014).

Schaerer, J; \& M. Dirven, 2001. El turismo rural en Chile. Experiencias de agroturismo en el Maule, la Araucanía y Los Lagos. Publicaciones de las Naciones Unidas, Santiago, Chile. 75 pp.

Servicio Nacional de Turismo. 2008. Glosario de Turismo. Publicaciones Gobierno de Chile, Santiago, Chile. 67 pp.

Servicio Nacional de Turismo. 2012. Estrategia nacional de turismo. Publicaciones Gobierno de Chile, Santiago, Chile. 101 pp.

Solsona, J. 2006. El turismo rural en Europa. Aportes y Transferencias, Universidad de Mar del Plata, Argentina. 10:25-35. 
Sustainability, Agri, Food and Environmental Research, 2014, 2(4): 11-22

ISSN: 0719-3726

Zamora, J. \& M. Barril, 2007. Turismo y vino: un estudio formativo sobre la evolución de las rutas del vino en Chile. Estudios y Perspectivas en Turismo, Centro de Investigaciones u Estudios Turísticos, Buenos Aires, Argentina. 16:173-194. 